\title{
sciendo

\section{CFD Modelling of Biomass Mixing in Anaerobic Digesters of Biogas Plants}

\author{
Fosca CONTI ${ }^{1 *}$, Abdessamad SAIDI ${ }^{2}$, Markus GOLDBRUNNER $^{3}$ \\ ${ }^{1}$ Department of Chemical Sciences, University of Padova, Padova, Italy \\ ${ }^{2,3}$ Institute of new Energy Systems, Technische Hochschule Ingolstadt, Ingolstadt, Germany
}

\begin{abstract}
Cut in greenhouse gas emissions, increment of energy from renewables and improvement in energy efficiency represent the three key targets for future energy systems. Among the available bioenergy technologies, biogas production via biodegradation and anaerobic digestion is a widely applied approach, not only to produce biofuels but also to manage industrial and domestic organic waste. Within the biogas production, a sufficient mixing of the organic mass is a crucial step to ensure high biogas yields by bacteria and enzymes. Measurements of the electric power consumption of biogas plants revealed that the electrical energy demand of the stirrer system has a high share of the total electricity consumption of a biogas plant. Investigations on real biogas digesters to optimize the mixing process are cost and time intensive. Therefore, laboratory prototypes and computational simulations represent promising alternatives to analyse and improve the efficiency of mixing systems. In this paper, a computational fluid dynamics (CFD) model is presented, which is applied to commercial stirring systems. The case of two propeller stirrers, located in diametrically opposite positions in a tank filled with ca. $1400 \mathrm{~m}^{3}$ of substrate is described in detail. For the simulation, the rheology of the fluid is adapted to a biomass with $12 \mathrm{wt} \%$ dry matter content and obeying the non-Newtonian generalized Ostwald-de Waele power law. The developed simulation procedure considers the rotation angle of each propeller and its height. A total of $\mathbf{4 4 1}$ mixing configurations are calculated and evaluated in terms of the technical benefit. The investigation reveals that locations of the rotors far away from the bottom and high rotational angles cause advantageous fluid dynamics.
\end{abstract}

Keywords - Anaerobic digester; biomass; cellulose; computational fluid dynamics (CFD); full scale biogas digester; laboratory digester; mixing; rheology; viscosity

\begin{tabular}{|lll|}
\hline Nomenclature & & $\mathrm{m} / \mathrm{s}$ \\
$v_{\mathrm{m}}$ & Flow velocity in the digester & $\mathrm{m} / \mathrm{s}$ \\
$v_{i}$ & Flow velocity in the $i$-component & degree \\
$\alpha$ & Side angle, horizontal, (x-y) plane, anticlockwise & $\mathrm{m}$ \\
$h$ & Height of the mixer in the digester & $\%$ \\
$\tau$ & Technical benefit parameter & - \\
$\varphi$ & Degree of fulfilment & - \\
$W$ & Weight of each criterion & \\
\hline
\end{tabular}

\footnotetext{
* Corresponding author.

E-mail address: fosca.conti@unipd.it

(C)2019 Fosca Conti, Abdessamad Saidi, Markus Goldbrunner.

This is an open access article licensed under the Creative Commons Attribution License (http://creativecommons.org/ licenses/by/4.0), in the manner agreed with Sciendo.
} 


\section{INTRODUCTION}

Among the various available technological methods to increase the efficiency of biogas production via anaerobic digestion, the optimization of the mixing system represents one of the most promising approaches [1]. Cost-benefit analyses indicate that mixing is the highest contributor to the total energy consumption in biogas plants [2]-[4]. Considering the total efficiency of the biogas plants, this parasitic contributor needs to be reduced and testing of different mixing regimes (i.e. spatial and operational arrangements of agitators) is required [5]. Laboratory scale experiments and computational simulations emerge as convenient and appropriate approaches to investigate the mixing in term of fluid dynamics [6], [7].

Computational fluid dynamics (CFD) allows detailed modelling of the mixing processes in anaerobic digesters [8]. In the last years, many simulation models have been presented. A state-of-the art regarding the application of CFD to investigate bioreactors is presented in [9]-[13]. To ensure a reliable model generation valid specification of the digester tank, stirrers, as well as initial and boundary initial conditions are required. Like every mathematical model, an experimental validation is necessary [14].

In this context, the present project is conducted in cooperation with UTS products GmbH, a leading German company in the field of biogas plant components, such as mixing systems, and pumps. The collaboration allows the development of a CFD based digester model considering the geometry of commercial mixing systems, which are widely applied in the biogas sector, enabling a comparison of the simulation results with the performance of commercial plants.

In this research, a mathematical model is developed with different geometric configurations and mixing systems in order to establish the best case, which can ensure a higher efficiency in terms of mixing quality. The modern StarCCM+ software, from CD-Adapco Siemens, is used to create three-dimensional geometries, to generate meshes, to solve the fluid dynamics by Ostwald-De Waele approach. Initially, the model was used to simulate the mixing in scaled-down laboratory digesters [7], [15] in order to validate the model. The laboratory digester was built in acryl glass to a scale of one to twelve and filled with an aqueous cellulose mixture, which was selected to represent the rheology of the substrate [16]. The fluid velocity was used as characterizing parameter for monitoring the mixing [17]-[19].

In the first part of the present paper a short summary of the methodological approach is presented. Afterwards, the new developed model for the full-scale digester and the results related to one mixing system in 441 possible configurations are discussed. The CFD calculations offer an additional method to plan real constructions. Indeed, they reduce the need of expensive post-construction field tests [20]-[23].

\section{Method and Procedure in a Scaled-Down Laboratory Digester}

\subsection{Methods of Mixing in Scaled-Down Laboratory Digester}

The mixing behaviour was analysed in a cylindrical tank made of poly(methylmethacrylate) to benefit of the transparent thermoplastic properties of the material. The following geometrical parameters were used to build up the tank: diameter of $1.5 \mathrm{~m}$, height of $0.7 \mathrm{~m}$ and wall thickness of $15 \mathrm{~mm}$. The tank was filled to a liquid depth of $46 \mathrm{~cm}$ to obtain approximately 8001 of liquid. Within the laboratory experiments, the three types of agitators shown in Fig. 1 are investigated: 
- Propeller with three rounded blades and diameter of $7.5 \mathrm{~cm}$, called RW-L;

- Propeller with three pointed blades and diameter of $12.5 \mathrm{~cm}$, called PW-L;

- Paddle, with four rectangular plates of $4.5 \cdot 7 \mathrm{~cm}$ dimension, called RP-L.

Label L stays for laboratory, to distinguish the present scale-down agitators from those in the real scale, which are discussed in the next paragraphs.

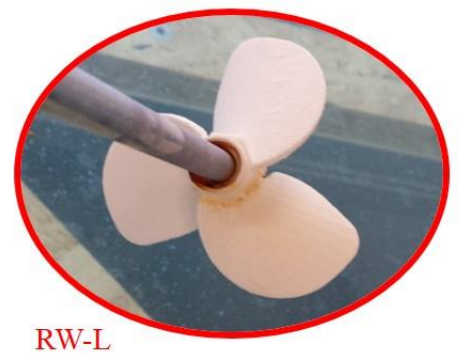

(a)

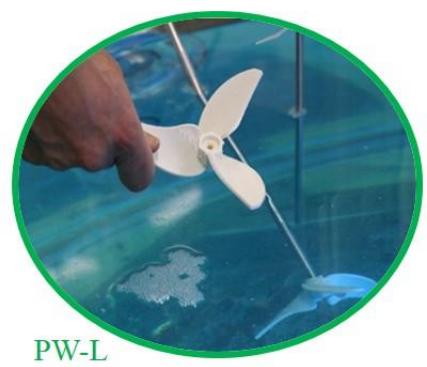

(b)

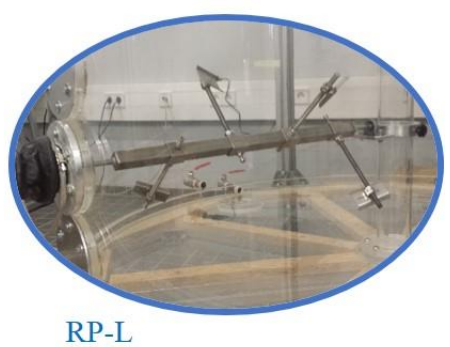

(c)

Fig. 1. Typology of the agitators: (a) propeller with three rounded blades and $\varnothing=7.5 \mathrm{~cm}$, called RW-L; (b) propeller with three pointed blades and $\varnothing=12.5 \mathrm{~cm}$, called PW-L; (c) paddle with four rectangular plates of $4.5 \cdot 7 \mathrm{~cm}$ dimension, called RP-L.

The laboratory tank was built with the purpose to replicate the digesters of full-scale biogas plants. It constitutes a prototype to study the mixing process in a scaled-down dimension, to reduce the system complexity of investigations on commercial digesters.

Three representative mixing configurations consisting of two agitators, which are placed in diametrically opposite positions, are tested in the laboratory digester. According to Fig. 2 the configurations present the following characteristics:

- M-1 includes a pointed blade propeller (PW) and a rounded blade propeller (RW) (Fig. 2(a));

- M-2 includes two pointed blades propellers (PW) (Fig. 2(b));

- M-3 includes a pointed blade propeller (PW) and a paddle system (RP) (Fig. 2(c)).

A detailed description of the mixing configurations is presented in [19].

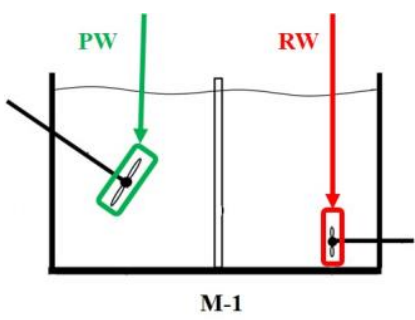

(a)

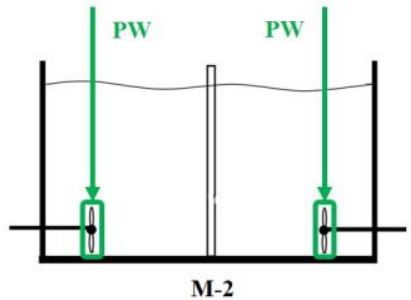

(b)

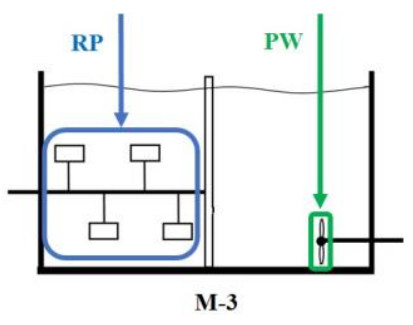

(c)

Fig. 2. Mixing configurations investigated in the laboratory digester: (a) M-1 includes a pointed blade propeller (PW) and a rounded blade propeller (RW); (b) M-2 includes two pointed blades propellers (PW); (c) M-3 includes a pointed blades propeller (PW) and a paddle system (RP).

In the laboratory digester, the biomass substrate was substituted with a water-cellulose solution, to guarantee transparency and easy handle. To have rheological parameters comparable with the real biomass, a sodium carboxymethyl cellulose at the concentration of 
$0.3 \mathrm{wt} \%$ was selected [16]. At room temperature, the $0.3 \mathrm{wt} \%$ water-cellulose solution shows an Ostwald-de Waele power-law behaviour, has non-Newtonian characteristics, a consistency factor of $0.05 \mathrm{~Pa} \cdot \mathrm{s}^{\mathrm{m}-1}$, a flow index of 0.35 , and a dynamic viscosity of $14 \mathrm{mPa} \cdot \mathrm{s}$ at a shear rate of $7 \mathrm{~s}^{-1}$, the selected $0.3 \mathrm{wt} \%$ water-cellulose solution shows representative flow characteristics at room temperature.

The process of mixing was investigated by detecting and analysing the velocity of the fluid in the different regions of the laboratory tank. The fluid velocity was mapped in the whole volume using an acoustic velocimeter, based on the Doppler Effect, and a particle image velocimetry (PIV) spectrometer, based on the photoexcitation of seeding particles. More details regarding the velocity measurements can be obtained in [19], [24].

The fluid dynamics results to be very complex, with patterns of fluid motion characterized by turbulent flows and other by laminar flow regimes, with the formation of vortexes and dead zones [25], [26]. For the evaluation of the components of the velocity vector, the xyz Cartesian coordinate system was selected according to the following setting: the $x-y$ plane was defined coincident with the base of the tank, the $\mathrm{x}$ - and $\mathrm{y}$-axis were defined crossing in the central position of the circular base of the tank and the z-axis was selected pointing up. A discussion of the measurement results is performed in [19]. Briefly, it was revealed that the maximum absolute values of the averaged velocities of the three components are in the following relation: $\left|\bar{v}_{x}\right|_{\max }>\left|\bar{v}_{y}\right|_{\max }>\left|\bar{v}_{z}\right|_{\max }$. The absolute values were between $4 \mathrm{~cm} / \mathrm{s}$ and $13 \mathrm{~cm} / \mathrm{s}$. The experimental data obtained using the acoustic velocimetry and the PIV spectroscopy were used to validate a computational model, which was recently developed to simulate the fluid dynamic in the laboratory digester on the basis of CFD calculations [15].

\subsection{CFD Modelling of Fluid Mixing in Scaled-Down Laboratory Digester}

A static mechanical simulation model was developed to investigate the mixing process in the cylindrical tank. The simulation procedure of the developed model covers the following steps:

1. Creation of the geometrical design of the cylindrical tank;

2. Creation of the geometrical design of the stirrers;

3. Generation of the grid;

4. Selection of the physical model;

5. Selection of the solvers;

6. Evaluation of the data;

7. Optimization of the model.

In Section 2.1 the experimental method to determine the mixing process is briefly described. The flow velocity of the water-cellulose mixture is used as a substrate substitute in the laboratory digester. The experimental results, obtained via acoustic Doppler effects and optical particle image spectroscopy are applied to validate the CFD model. Analogously to the laboratory experiments, the three different mixing configurations were created using the two propeller mixers and the paddle system. The geometrical parametrization of the three stirrers was drawn using 3D-CAD. The developed stirrer geometries are shown in Fig. 3(a) and Fig. 3(b). As illustrated in Fig. 4(b) the stirrer geometries are included inside the cylindrical volume of the mixing fluid. Then the meshes were created, as shown in Fig. 3(c) and Fig. 4(a).

The software Star-CCM+ was used to generate the meshes. There are different possible meshing strategies, in the relation to the system to mesh: surface or volume. Here, the following four meshers were carefully chosen [15]: for the surface mesh, the Surface Remesher and the Automatic Surface Repair were selected. The latter one was used to identify 
and solve problems. For the volume mesh, the Polyhedral Mesher and the Advancing Layer Mesher were selected. To contemplate the wall boundary effects, the standard $k$ - $\omega$ model was applied. On the wall and bottom of the tank, no-slip conditions were set because more accurate, whereas the fluid surface on the top (transition to gas) was modelled with slip conditions. More details are reported in [15].

The basic cell size was set at $1.5 \mathrm{~cm}$ diameter, resulting in a total number of cells of 250,000 .

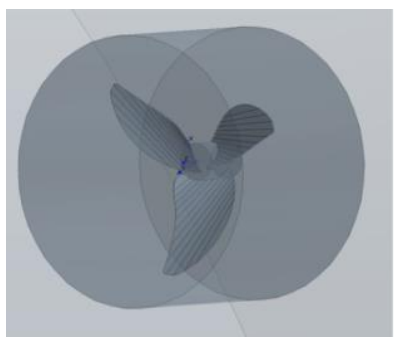

(a)

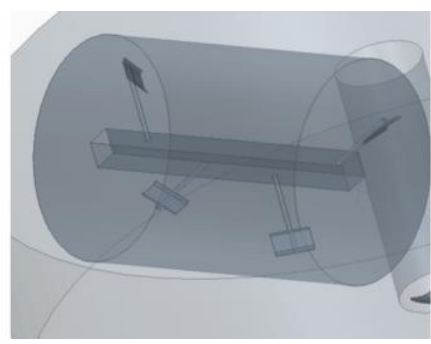

(b)

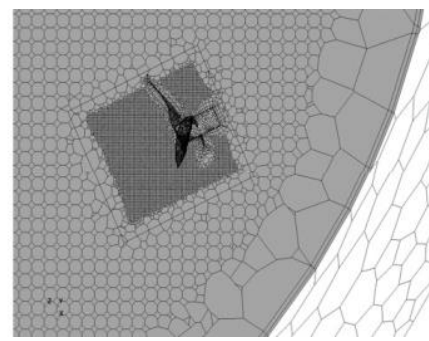

(c)

Fig. 3. Geometry imported in the CFD model for: (a) propeller RB with rounded blades; (b) paddle system RP with rectangular plates; (c) propeller PB with pointed blades. In (c) the meshes of the regions and sub-regions inside the cylindrical volume of the laboratory digester are shown.

The model is based on the assumption that the homogeneity of the fluid is the main determining parameter to evaluate the quality of the mixing process. The homogeneity can be quantified by the flow velocity vector and by its components in the $\mathrm{x}, \mathrm{y}$, and $\mathrm{z}$ direction of the axis system. Therefore, a comprehensive analysis of the velocity fields is determined by CFD calculations. The output parameters of the CFD simulations are the flow velocity vector in the digester and its three spatial components. A near uniform distribution in the three directions indicates substrate homogeneity.

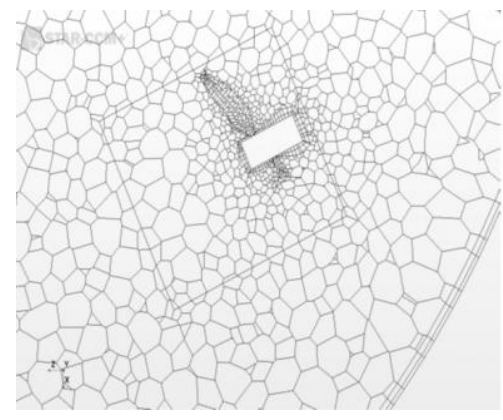

(a)

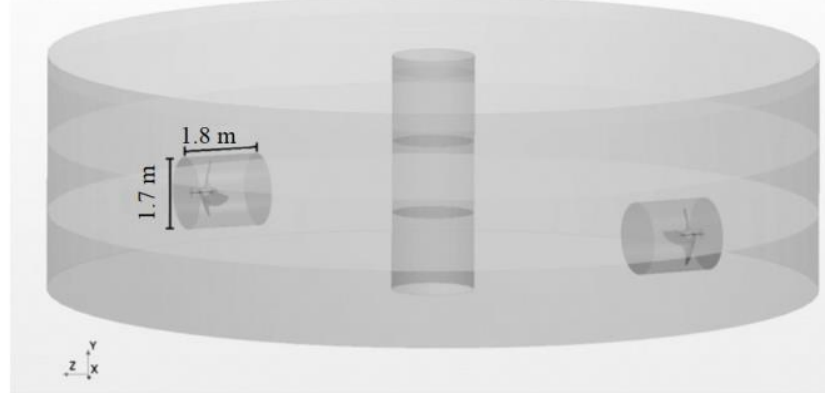

(b)

Fig. 4. Geometry of regions and sub-regions imported in the CFD model: (a) mesh around propeller RW; (b) whole digester with the presence of two propeller mixers placed in diametrically opposite positions and in M-2 configuration.

In Fig. 5 the flow velocity for the three mixing configuration is visualized.

The results from the CFD calculations reveal a high consistency between simulation results and experimental values obtained by PIV spectroscopy and acoustic velocimetry analysis [15], [19]. Based on the successfully performed experimental validation, an up-scaling of the CFD model is conducted to simulate the mixing process in full-scale anaerobic digesters. 
For this reason, the characteristic of mixers used in biogas plants are presented and discussed in the next paragraph.

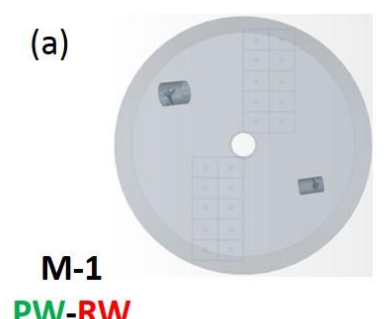

PW-RW
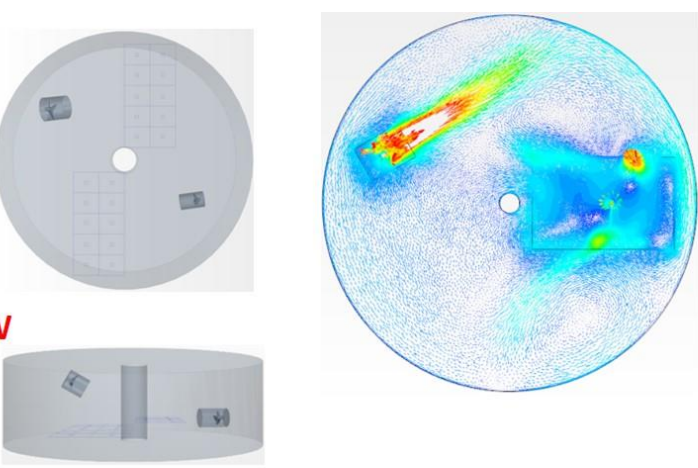

(b)

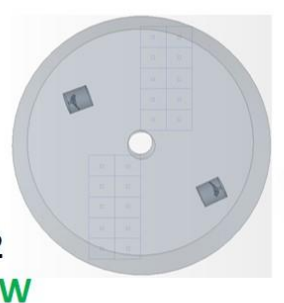

PW-PW
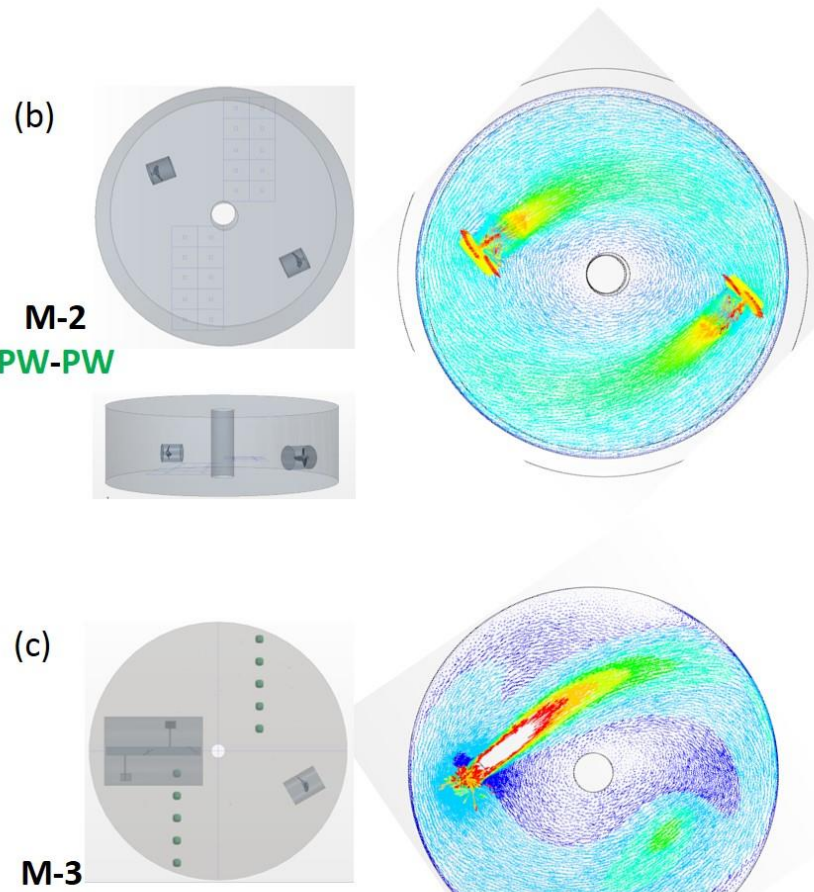

RP-PW

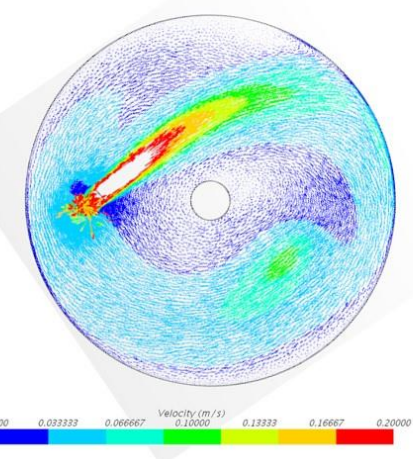

Fig. 5. Simulations results from CFD calculations: CAD models and visualization of the flow velocity in the three mixing configurations: (a) M-1, with a pointed blade propeller (PW) and a rounded blade propeller (RW); (b) M-2, with two pointed blade propellers (PW); (c) M-3 with a paddle system (RP) and a pointed blade propeller (PW) [15]. 


\section{Method and Procedure in a Full-Scale Anaerobic Digester}

\subsection{Methods of Mixing in Full-Scaled Laboratory Digester}

Here the project is conducted in collaboration with the German UTS Products GmbH and some specific biogas plants related to UTS. Therefore, the investigation is focused on the typologies of mixer used by UTS. They are reported in Fig. 6. The label " $R$ " is used to distinguish the real $(\mathrm{R})$ mixers from the laboratory (L) mixers, which were shown in Fig. 1 and labelled consequently with " $L$ ".

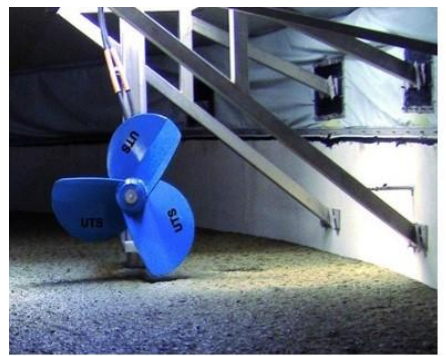

RW-R

(a)

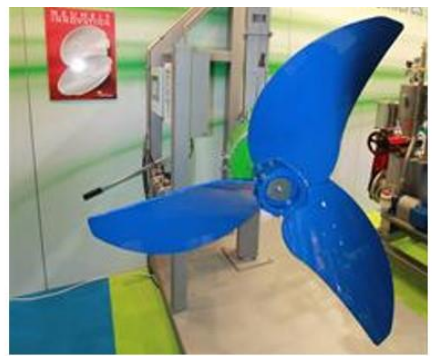

PW-R

(b)

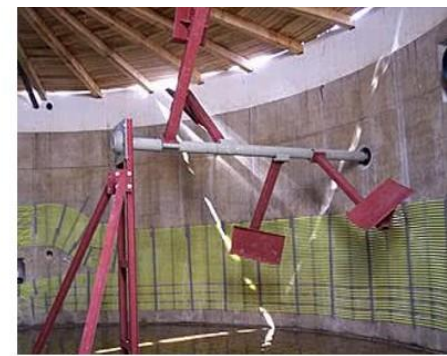

RP-R

(c)

Fig. 6. Typology of the agitators used in the anaerobic digesters of biogas plants: (a) propeller with three rounded blades and $\varnothing=0.9 \mathrm{~m}$, called RW-R; (b) propeller with three pointed blades and $\varnothing=1.5 \mathrm{~m}$, called PW-R; (c) paddle with four rectangular plates of $54 \cdot 84 \mathrm{~cm}$ dimension, called RP-R.

In Table 1 the main characteristic of the laboratory and real mixers are reported. The values of geometrical dimension (diameter) of the real mixers are those used by the UTS partners. The values for the laboratory mixers are scaled down of a factor 12 .

TABLE 1. TyPES AND CHARACTERISTICS OF THE INVESTIGATED MIXERS

\begin{tabular}{llllll}
\hline $\begin{array}{l}\text { Name of } \\
\text { mixer }\end{array}$ & Description & $\begin{array}{l}\text { Diameter in } \\
\text { reality, cm }\end{array}$ & $\begin{array}{l}\text { Diameter in } \\
\text { laboratory, cm }\end{array}$ & $\begin{array}{l}\text { Rotation speed } \\
\text { in reality, rpm }\end{array}$ & $\begin{array}{l}\text { Rotation speed in } \\
\text { laboratory, rpm }\end{array}$ \\
\hline RW & Propeller with 3 rounded blades & 150 & 12.5 & $80-50$ & 140 \\
PW & Propeller with 3 pointed blades & 94 & 7.8 & $120-170$ & 238 \\
RP & System with 4 rectangular paddles & 422 & 35.2 & Confident & 15 \\
\hline
\end{tabular}

\subsection{CFD Modelling of Fluid Mixing in Full-scale Anaerobic Digesters}

In the present study, the CFD model of the mixing process was evaluated considering a configuration: with two mixers, located in diametrically opposite positions and constituted by a rounded blades propeller and a pointed blades propeller. The developed simulation procedure considers the following variables: The angle $\alpha$ of the two propellers and their heights, $h$. The variation range, which is shown in Fig. 7, results in a total number of 441 mixing configurations. 


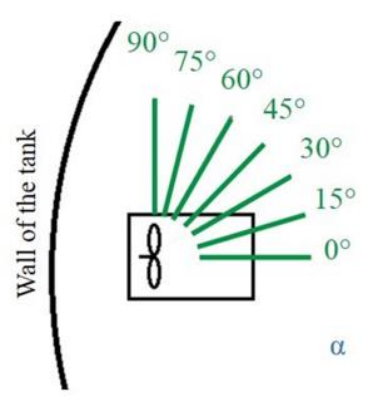

(a)

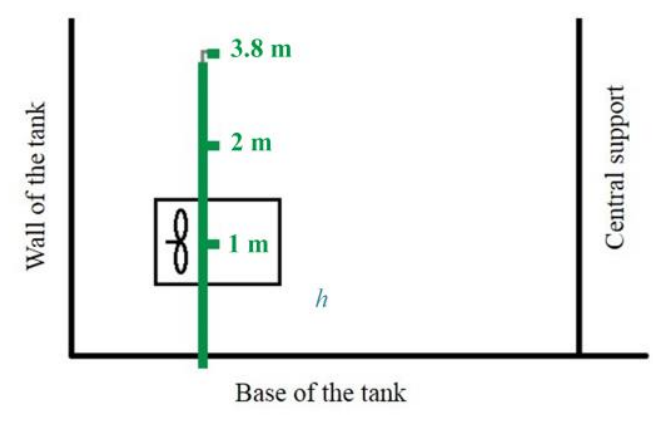

(b)

Fig. 7. Geometrical parameters of the mixers and corresponding values used in the CFD simulations: (a) angle of axis of the mixer; (b) height of the axis of the mixer.

For the model-based sensitivity analysis the rheology of the fluid was adapted to a real substrate mixture with 12 wt \% dry matter content, while the consistency factor and flow index of the power law conditions were set to the values of $16.77 \mathrm{~Pa} \cdot \mathrm{s}^{\mathrm{n}}$ and 0.35 , respectively.

As suitable simplification already used in the CFD model for scaled-down laboratory digester [15], the $k$ - $\omega$ model was applied to contemplate the wall boundary effects. On the wall and bottom of the tank, no-slip conditions were set, whereas the fluid surface on the top was modelled with slip boundary conditions.

\section{RESUlTS AND DisCUSSION}

The results of the CFD model are considered in the sixteen regions shown in Fig. 8 . The digester is divided into a bottom and a top section. For each section, eight regions are defined. The regions have cylindrical shapes with an empty internal part because of the mechanical support, which is present in almost all biogas plants.

The flow velocity is evaluated by the model in the three axial components and as magnitude of the velocity vector. The velocity magnitude and $\mathrm{z}$-component in the 16 regions are plotted in Fig. 9 depending on the angle of the second mixer. The velocity in the bottom regions shows a strong maximum in the profile, which is very weak in the profiles of the top regions. By increasing the angle of the mixer, the maximum value of the velocity increases, which suggests that with high angles of the mixers the mixing is more efficient. In the top regions the velocity is generally less intense.

It is interesting to analyse the z-component of the velocity because of the effect of the gravitational force. The plot of Fig. 9(b) underlines the complex vertical flow behaviour, since the profiles do not show particular tendencies. The dynamics result to be a combination of different phenomena, so that the different patterns of fluid motion could be characterized by turbulent and laminar flow regimes, with the formation of vortexes [25], [26].

The results of the CFD calculations were analysed to estimate the advantageous configurations in terms of the propeller position (angle and location). For this purpose, 6 parameters were defined as criteria. Five parameters are related to the flow velocity of the fluid. while the sixth parameter used as criterion is the torque required to rotate the mixers. The torque is evaluated to characterize the required energy demand. 

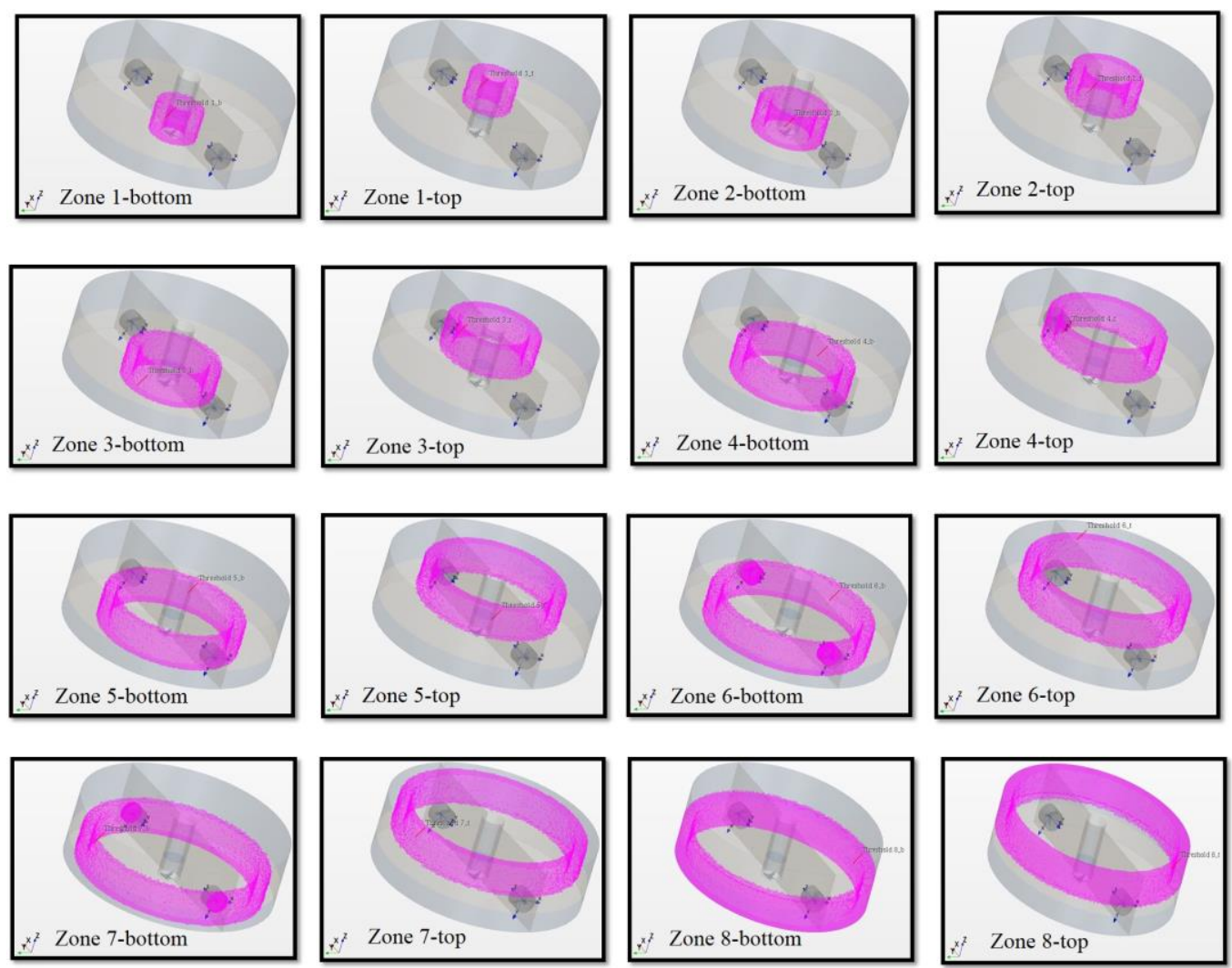

Fig. 8. Shape of partitions for the 8 bottom and 8 top areas in 3D environmental obtained by CFD simulation.

In Table 2 the six parameters used as criteria are specified. Each criterion was characterized by a weight $(W)$ between 4 and 2 . Recently, only the first four criteria are applied to evaluate the CFD model in the 1:12 scaled-down laboratory digester described in previous sections 2.1 and 2.2. The weight values were 4, 3, 2, and 1 [15]. For the present study on a full-scale digester, two new criteria are added and for the first four the values are 4, 3, 2, and 2, as listed in the last column of Table 2. The weight value for the vertical movement has been increased from 1 to 2 compared to the previous study [15]. Poorly mixed volume along the Z-direction can cause solid parts floating at the surface or settling at the bottom. Both phenomena are to avoid to obtain a good mixing. Therefore, the previous weighting of merely 1 was an underestimation of the complexity of the process. Additionally, for each criterion, five intervals of values were established. For each interval, a degree of fulfilment $(\varphi)$ was selected. The following values for $\varphi$ was chosen: $0,1,3,5$ and 9. Table 3 summarizes the degree of fulfilment for the different ranges of the criterion parameters.

The advantage of each mixing configuration was quantified by the parameter $\tau$, called technical benefit, which is expressed in percentage and calculated according to the following equation:

$$
\tau=\frac{\sum_{l=1}^{6} \varphi_{i} \cdot w_{i}}{144} \cdot 100
$$




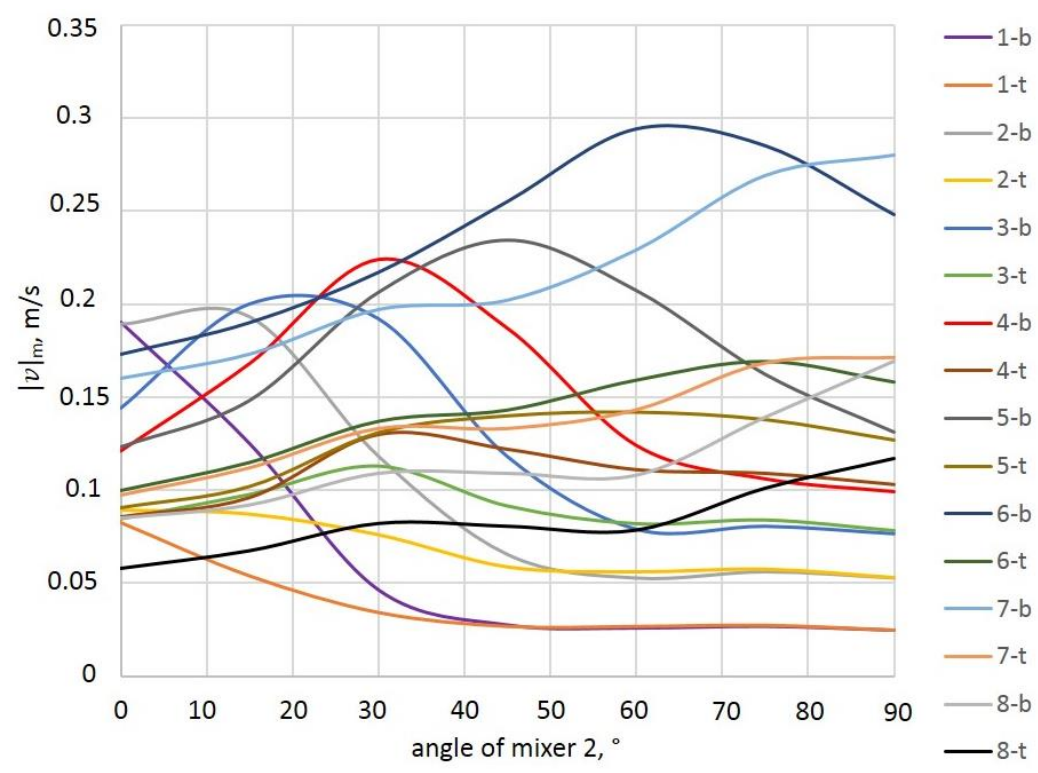

(a)

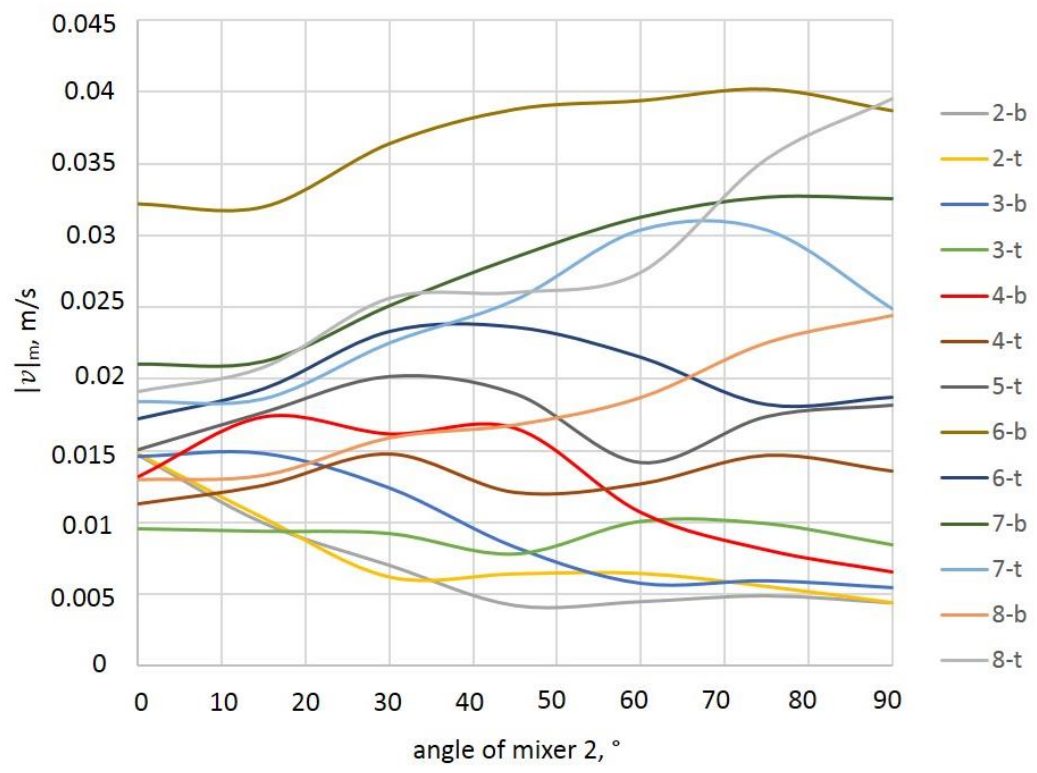

(b)

Fig. 9. Velocity profiles of the bottom and top zones depicted in Fig. 8 as function of the angle of mixer 2: (a) averaged value of flow velocity; (b) Z-component of the flow velocity. 
TABle 2. CRITERIA AND EVAluation WeIGHTS USED FOR BENEFIT ANALYSIS

\begin{tabular}{|c|c|c|c|}
\hline Parameter & Criterion & Description & $\begin{array}{l}\text { Criterion's } \\
\text { weight } W\end{array}$ \\
\hline$v_{\mathrm{m}}[15]$ & Flow velocity digester & Indication of flow intensity & 4 \\
\hline$v_{\mathrm{x}}, v_{\mathrm{y}}, v_{\mathrm{z}}[15]$ & $\begin{array}{l}\text { Uniform distribution of flow velocity } \\
\text { vector components ( } 1 / 3 \text { each, } 33 \%)\end{array}$ & Indication of homogeneous mixing & 3 \\
\hline$Z \%[15]$ & $\begin{array}{l}\text { Total amount of vertical up/down flow } \\
\text { velocity }\end{array}$ & $\begin{array}{l}\text { Horizontal (circular) movement dominates in } \\
\text { cylindrical digesters, vertical up/down amount of } \\
\text { z-component indicates better mixing }\end{array}$ & 2 \\
\hline $\begin{array}{l}Z+\%, z-\% \\
{[15]}\end{array}$ & $\begin{array}{l}\text { Uniform amount of positive (up) and } \\
\text { negative (down) of } z \text { vertical } \\
\text { component }(1 / 2 \text { each, } 50 \%)\end{array}$ & $\begin{array}{l}\text { Avoidance of an up- or down-ward movement } \\
\text { tendency }\end{array}$ & 2 \\
\hline$Z_{\mathrm{GI}}$ & Zone specific uniformity index & $\begin{array}{l}\text { Describe the ratio between average velocity of } \\
\text { the zone }\left(v_{\mathrm{n}}\right) \text { and the whole digester }\left(v_{\mathrm{m}}\right) \\
Z_{\mathrm{GI}}=v_{\mathrm{n}} / v_{\mathrm{m}}\end{array}$ & 2 \\
\hline$T$ & Torque & $\begin{array}{l}\text { Parameter to determine the required performance } \\
\text { in term of energy }\end{array}$ & 3 \\
\hline
\end{tabular}

Eq. (1) relates the degree of fulfilment with the criterion weight. The ideal score scenario is represented by the term 144 in the denominator, where all six criteria have the maximum degree of fulfilment. It was used to calculate the technical benefit of all the $441 \mathrm{mixing}$ configurations. As expected by the above analysis of the patterns of the velocity profiles reported in Fig. 9, the configurations with rotors at high angles have higher values of $\tau$. On the opposite, the configurations with low values of $\alpha$ result to have a low benefit.

TABLE 3. DEGREE OF FULFILMENT ( $\varphi$ ) FOR DIFFERENT RANGES OF CRITERION PARAMETERS

\begin{tabular}{llllll}
\hline Criterion & $\varphi=0$ & $\varphi=1$ & $\varphi=3$ & $\varphi=5$ & $\varphi=9$ \\
\hline$v_{\mathrm{m}}, \mathrm{m} / \mathrm{s}$ & $<0.10$ & $<0.11$ & $<0.12$ & $<0.13$ & $>0.13$ \\
$v_{i}, \%$ & $>30$ & $>25$ & $>20$ & $>15$ & $<15$ \\
$Z \%, \%$ & $<21$ & $<24$ & $<27$ & $<30$ & $>30$ \\
$Z+\%, \%$ & $>16$ & $<16$ & $<12$ & $<8$ & $<4$ \\
\hline
\end{tabular}

The position of the two mixers show also a tendency. The location near the bottom results to be less efficient respect to the location on the top. In Table 4 are reported 8 configurations of the total 441. The parameter Technical benefit is expressed in percentage and reported in the last column. The values are between 72.01 and 24.50 and Table 4 shows the best five and worst three configurations according to the technical benefit value. The use of the parameter $\tau$ is crucial to establish criteria on the construction of the mixing system in anaerobic digesters. 
Table 4. Technical Benefit $(\tau)$ OF Simulation at DifFerent Angles $(\alpha)$ AND Height $(h)$ OF THE Two MiXers Placed In Diagonal Opposite Positions

\begin{tabular}{llllll}
\hline No. & $\alpha$ of RW, ${ }^{\circ}$ & $\alpha$ of $\mathrm{PW},{ }^{\circ}$ & $h$ of RW, m & $h$ of PW, m & $\tau, \%$ \\
\hline 1 & 75 & 75 & 3.8 & 3.8 & 72.01 \\
2 & 90 & 75 & 2 & 3.8 & 71.26 \\
3 & 90 & 60 & 3.8 & 3.8 & 70.98 \\
4 & 90 & 60 & 2 & 3.8 & 70.94 \\
5 & 90 & 90 & 2 & 1 & 70.78 \\
439 & 15 & 15 & 1 & 2 & 26.77 \\
440 & 30 & 15 & 2 & 1 & 26.63 \\
441 & 15 & 15 & 1 & 1 & 24.50 \\
\hline
\end{tabular}

In the present study, the parameter velocity dominates the discussion. High velocity was related to high homogeneity of the fluid and therefore high production of biogas. The biological aspect of the biomass is not considered in the model. Indeed, a complex microbial consortium of bacteria is present, which is responsible of the efficiency of the fermentation [27]-[29]. High mixing intensities create high shear rates large enough to break up the microbial flocculation structure and to inhibit the operation of methanogenic bacteria and enzymes.

\section{CONClusions}

The mixing system in anaerobic digesters of biogas plants has a high energy demand, decreasing total plant efficiency. Cost-benefit analysis indicate that mixing is the highest negative contributor to the total energy management and budget in the plant. To reduce this parasitic contributor, operational conditions and geometrical parameters need to be optimized. Within the present study, method methodology for CFD based technical evaluation of different configurations is introduced. The exemplarily analysed configuration includes two propeller rotors pointed in opposite positions. The rotors were evaluated regarding their position inside the digester. The investigations revealed that locations of the rotors far away from the bottom and high rotation angles cause advantageous fluid dynamics characterized by high values of velocity. Further configurations, including paddle systems, are in progress.

\section{ACKNOWLEDGEMENT}

This work has been supported by the German Federal Ministry of Education and Research within the program "Forschung an Fachhochschulen"' under the grants 22402215 and BioOpt-Mix 03FH031PX4.

The authors would like to thank UTS Products GmbH in Dorfen (Germany) for helpful cooperation. F. Conti is grateful to the University of Padova (Italy) for providing the opportunity to spend research periods in THI Ingolstadt.

\section{REFERENCES}

[1] Lebranchu A., et al. Impact of shear stress and impeller design on the production of biogas in anaerobic digesters. Bioresource Technology 2017:245(A):1139-1147. doi:10.1016/j.biortech.2017.07.113

[2] Naegele H. J., et al. Electric energy consumption of the full scale research biogas plant 'unterer lindenhof': results of longterm and full detail measurements. Energies 2012:5(12):5198-5214. doi:10.3390/en5125198 
[3] Sonnleitner M. Ecological and economic optimization of biogas plants. MPhil Thesis. Leicester: De Montfort University, 2012.

[4] Singh B., Szamosi Z., Simenfalvi Z. State of the art on mixing in an anaerobic digester: a review. Renewable Energy 2019:141:922-936. doi:10.1016/j.renene.2019.04.072

[5] Kowalczyk A., et al. Different mixing modes for biogas plants using energy crops. Applied Energy 2013:112:465472. doi:10.1016/j.apenergy.2013.03.065

[6] Wiedemann L., et al. Mixing in Biogas Digesters and Development of an Artificial Substrate for Laboratory-Scale Mixing Optimization. Chemical Engineering \& Technology 2017:40:238-247. doi:10.1002/ceat.201600194

[7] Conti F., et al. Mixing of a Model Substrate in a Scale-down Laboratory Digester and Processing with a Computational Fluid Dynamics Model. Proc. of 26th EUBCE-European Biomass Conference and Exhibition, Copenhagen 2018:811-815. doi:10.5071/26thEUBCE2018-2CV.5.34

[8] Leonzio G. Study of mixing systems and geometric configurations for anaerobic digesters using CFD analysis. Renewable Energy 2018:123:578-589. doi:10.1016/j.renene.2018.02.071

[9] Bridgeman J. Computational fluid dynamics modeling of sewage sludge moxing in an anaerobic digester. Advances in Engineering Software 2012:44(1):54-62. doi:10.1016/j.advengsoft.2011.05.037

[10] Dapelo D., Alberini F., Bridgeman J. Euler-Lagrange CFD modelling of unconfined gas mixing in anaerobic digestion. Water Res. 2015:85:497-511. doi:10.1016/j.watres.2015.08.042

[11] Ding J., et al. CFD optimization of continuous stirred-tank (CSTR) reactor for biohydrogen production. Bioresource Technology 2010:101:7005-7013. doi:10.1016/j.biortech.2010.03.146

[12] Keshtkar A., et al. Mathematical modeling of nonideal mixing continuous flow reactors for anaerobic digestion of cattle manure. Bioresource Technology 2003:87(1):113-124. doi:10.1016/S0960-8524(02)00104-9

[13] Vesvikar M. S., Al-Dahhan M. Flow pattern visualization in a mimic anaerobic digester using CFD. Biotechnology in Bioengineering 2005:89(6):719-732. doi:10.1002/bit.20388

[14] Lopez-Jimenez P. A., et al. Application of CFD methods to an anaerobic digester: the case of Ontinyent WWPT, Valencia, Spain. Journal of Water Process Engineering 2015:7:131-140. doi:10.1016/j.jwpe.2015.05.006

[15] Wiedemann L., et al. Modeling Mixing in Anaerobic Digesters with Computational Fluid Dynamics Validated by Experiments. Chemical Engineering \& Technology 2018:41:2101-2110. doi:10.1002/ceat.201800083

[16] Conti F., et al. Thermal behaviour of viscosity of aqueous cellulose solutions to emulate biomass in anaerobic digesters. New Journal of Chemistry 2018:42:1099-1104. doi:10.1039/c7nj03199h

[17] Wiedemann L., et al. Investigation and optimization of the mixing in a biogas digester with a laboratory experiment and an artificial model substrate. Proceeding of 25th EUBCE-European Biomass Conference and Exibition, Stockholm 2017:889-892. doi:10.5071/25thEUBCE2017-2CV.4.14

[18] Sindall R. C., Bridgeman J., Carliell-marquet C. Velocity gradient as a tool to characterrize the link between mixing and biogas production in anaerobic waste digesters. Water Sci. Technol. 2013:67:2800-2806.

[19] Conti F., et al. Monitoring the mixing of an artificial model substrate in a scale-down laboratory digester. Renewable Energy 2019:132:351-362. doi:10.1016/j.renene.2018.08.013

[20] Shen F., et al. Improving the mixing performances of rice straw anaerobic digestion for higher biogas production by computational fluid dynamics (CFD) simulation. Applied Biochem. Biotechnol. 2013:171626-642.

[21] Gerogiorgis D. I., Ydstie B. E. Multiphysics CFD modeling for design and simulation of a multiphase chemical reactor. Chemical Engineering Research and Design 2005:83(6):603-610. doi:10.1205/cherd.04364

[22] Atta A., Roy S., Nigam K. D. P. A two-phase Eulerian approach using relative permeability concept for modeling of hydrodynamics in trickle-bed reactors at elevated pressure. Chemical Engineering Research and Design 2010:88(3):369-378. doi:10.1016/j.cherd.2009.06.011

[23] Celik I. B., et al. Procedure for estimation and reporting of uncertainty due to discretization in CFD applications. Journal of Fluid Engineering 2008:130(7):0780011-0780014. doi:10.1115/1.2960953

[24] Conti F., et al. Effect of mixing of waste biomass in anaerobic digesters for production of biogas. IOP Conf. Series: Materials Sci. Eng. 2018:446:012011. doi:10.1088/1757-899X/446/1/012011

[25] Wu B. CFD investigation of turbulence models for mechanical agitation of non-Newtonian fluids in anaerobic digesters. Water Research 2011:45(5):2082-2094. doi:10.1016/j.watres.2010.12.020

[26] Alexopoulos A. H., Maggioris D., Kiparissides C. CFD analysis of turbulence non-homogeneity in mixing vessels: a two compartment model. Chemical Engineering Science 2002:57(10):1735-1752. doi:10.1016/S00092509(02)00053-2

[27] Trentini M., Lorenzon M., Conti F. Biotechnology to investigate the microbial community responsible of biogas production from biomass. Proceeding of $26^{\text {th }}$ EUBCE-European Biomass Conference and Exhibition, Copenhagen, 2018:816-820. doi:10.5071/26thEUBCE2018-2CV.5.35

[28] Castellan N., Conti F. Molecular biotechnology to improve biofuel production from biomass. Proceeding of $27^{\text {th }}$ EUBCE-European Biomass Conf. and Exhibition, Lisbon, 2019:951-957. doi:10.5071/27thEUBCE2019-2CV.6.24

[29] Djossou A., Conti F. Mesophilic and thermophilic bacteria in anaerobic digestion process. Proceeding of $27^{\text {th }}$ EUBCE-European Biomass Conf. and Exhibition, Lisbon, 2019:942-945. doi:10.5071/27thEUBCE2019-2CV.6.9 